๑Ю. Б. Дроздовська

Тернопільсъкий державний медичний університет ілені І. Я. Горбачевсъкого МОЗ України

Медичний центр «Клініка професора С. Хліля», м. Тернопіль

\title{
ОЦІНКА ОВАРІАЛЬНОГО РЕЗЕРВУ В ЖІНОК ІЗ БЕЗПЛІДДЯМ НА ФОНІ ЛЕЙОМІОМИ МАТКИ В ПРОГРАМАХ ДОПОМГЖНИХ РЕПРОДУКТИВНИХ ТЕХНОЛОГІЙ
}

\begin{abstract}
Мета дослідження - підвищити частоту настання вагітності у безплідних жінок із лейоміомою матки (лм) шляхом аналізу основних фракторів розвитку даної патології та оптимізації лікувально-профрілактичного комплексу.

Матеріали та методи. Рандомізоване проспективне клінічне дослідження проведено серед 175 (29,0 \%) жінок репродуктивного віку, в яких діагностовано ЛМ, та в контрольній групі (КГ) із 32 соматично здорових жінок із нормальною менструальною та репродуктивною функціями, яких було поділено на такі групи: основна (ОГ) А група - 137 жінок із лМ із запропонованим лікуванням; порівняння (ПГ) Б група - 38 жінок із ЛМ та загальноприйнятим лікуванням.

Результати дослідження та їх обговорення. Проведено оцінку стану репродуктивної системи за допомогою ультразвукового, гормонального моніторингу для прогнозування ймовірної відповіді яєчників на стимуляцію. Детально 3 практичної точки зору оцінено отримані результати ультразвукового, гормонального моніторингу в жінок із безпліддям на фоні лейоміоми матки для подальшого лікування. Адекватний кровообіг - важливий фрактор для фрункціонування яєчників. У випадку прогнозування «бідної» відповіді яєчників на їх контрольовану стимуляцію середня пікова систолічна швидкість (ПСШ) стромальних артерій була в 1,68 раза нижча, ніж у жінок контрольної групи. Виявлено позитивну кореляцію між кількістю введених

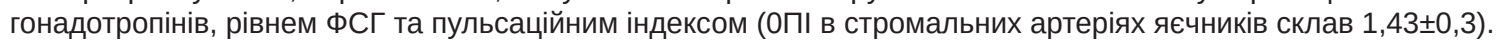

Висновок. Проведення ретельної оцінки оваріальної відповіді дає змогу правильно вибрати тактику лікування та дозу препаратів, а також відстежити результати, врахувавши отримані дані.
\end{abstract}

Ключові слова: безпліддя; гормональний гомеостаз; ультразвуковий моніторинг; оваріальний резерв.

ОЦЕНКА ОВАРИАЛЬНОГО РЕЗЕРВА У ЖЕНЩИН С БЕСПЛОДИЕМ НА ФОНЕ ЛЕЙОМИОМЫ МАТКИ В ПРОГРАММЕ ВСПОМОГАТЕЛЬНЫХ РЕПРОДУКТИВНЫХ ТЕХНОЛОГИЙ

Цель исследования - повысить частоту наступления беременности у бесплодных женщин с лейомиомой матки (ЛМ) путем анализа основных фракторов развития данной патологии и оптимизации лечебно-профилактического комплекса.

Материалы и методы. Рандомизированное проспективное клиническое исследование проведено среди 175 (29,0 \%) женщин репродуктивного возраста, у которых диагностировано ЛМ, и в контрольной группе (КГ) из 32 соматически здоровых женщин с нормальной менструальной и репродуктивной функцией, которые были разделены на следующие группы: основная (ОГ) А группа - 137 женщин с лМ с предложенным лечением; сравнения (СГ) Б группа - 38 женщин с лМ и общепринятым лечением.

Результаты исследования и их обсуждение. Проведена оценка состояния репродуктивной системы с помощью ультразвукового, гормонального мониторинга для прогнозирования возможной реакции яичников на стимуляцию. Подробно с практической точки зрения оценены полученные результаты ультразвукового, гормонального мониторинга у женщин с бесплодием на фоне лейомиомы матки для дальнейшего лечения. Адекватное кровообращение - важный фрактор для функционирования яичников. В случае прогнозирования «бедного» ответа яичников на контролируемую стимуляцию яичников средняя пиковая систолическая скорость (ПСШ) стромальных артерий была в 1,68 раза ниже, чем у женщин контрольной группы. Выявлена положительная корреляция между количеством введенных гонадотропинов, уровнем ФСГ

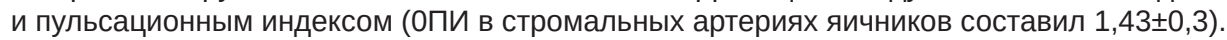

Вывод. Проведение тщательной оценки овариального ответа позволяет правильно выбрать тактику лечения и дозу препаратов, а также отследить результаты, учитывая полученные данные.

Ключевые слова: бесплодие; гормональный гомеостаз; ультразвуковой мониторинг; овариальный резерв.

ASSESSMENT OF OVARIAN RESERVE IN WOMEN WITH INFERTILITY AND UTERINE LEIOMYOMA IN ASSISTED REPRODUCTIVE TECHNOLOGY PROGRAMS

The aim of the study - to increase the incidence of pregnancy in infertile women with uterine leiomyoma by analyzing the main factors in the development of this pathology and optimizing the treatment and prevention complex.

Materials and Methods. A randomized prospective clinical study was conducted among 175 (29.0\%) women of reproductive age who were diagnosed with uterine leiomyoma (UL) and a control group (CG) of 32 somatically healthy women with normal menstrual and reproductive functions, who were divided into the following groups: Main Group (MG) A - 137 women with UL receiving the proposed treatment; Comparison Group (CG) B - 38 women with UL receiving conventional treatment.

Results and Discussion. The condition of the reproductive system was assessed using ultrasound and hormonal monitoring to predict the probable response of the ovaries to stimulation. The results of ultrasound and hormonal monitoring in women with infertility and uterine leiomyoma were evaluated in detail from a practical viewpoint to determine further treatment. Adequate blood circulation is an important factor for ovarian function. For patients where a "poor" ovarian response to controlled ovarian stimulation was predicted, the mean peak systolic velocity (PSV) in the stromal arteries was 1.68 times lower than in women from the control 
group. There was a positive correlation between the amount of injected gonadotropins, FSH levels and pulsatility index (OPI in the stromal arteries of the ovaries was $(1.43 \pm 0.3)$.

Conclusion. A thorough assessment of the ovarian response allows the doctor to choose the correct treatment tactics and dose of drugs, as well as to monitor the results, taking into account the data obtained.

Key words: infertility; hormonal homeostasis; ultrasound monitoring; ovarian reserve.

ВСТУП. Розвиток допоміжних репродуктивних технологій в усьому світі спрямований на подолання безпліддя $[1,3,5,9]$. Настання вагітності в результаті програм запліднення in vitro (3ІВ) коливається від 10 до 60 \% для різних груп пацієнтів і рідко перевищує 30 \% бар'єр [5, 8, 10, 13, 16]. Цей показник залежить від багатьох фракторів: віку пацієнток, причини безпліддя, застосованої схеми індукції суперовуляції, якості аспірованих ооцитів, показників спермограми, здатності ендометрія до імплантації отриманих ембріонів $[2,6,18,19]$. Лейоміома матки (ЛМ) $€$ одним із провідних чинників розвитку безпліддя, як вторинного, так і первинного, яка виявляється в 13,3-24,0\% $[4,7,12,15]$. У результаті одночасної взаємодії цілого комплексу причинно-наслідкових сракторів відбувається зниження частоти імплантації при безплідді на фоні ЛМ, що знижує розвиток ооцитів та ембріонів і пригнічує секреторну трансорормацію ендометрія [8, 11, 14, 20, 21].

Таким чином, оцінка методу оптимізації реалізації репродуктивної функції з цією патологією є актуальним завданням гінекології та репродуктології.

МЕТА ДОсЛІДЖЕННЯ - підвищити частоту настання вагітності у безплідних жінок на фоні лейоміоми матки шляхом аналізу основних фракторів розвитку даної патології та оптимізації лікувально-профрілактичного комплексу.

МАТЕРІАЛИ ТА МЕТОДИ. Рандомізоване клінічне дослідження виконували впродовж 2014-2020 рр. на базі Медичного центру «Клініка профресора С. Хміля». На I етапі проведено аналіз амбулаторних історій 603 жінок репродуктивного віку з операціями на органах малого таза, в подальшому в проспективний аналіз було включено 175 (29,0 \%) жінок репродуктивного віку, в яких діагностовано ЛМ, та контрольну групу (КГ) 32 соматично здорових жінок з нормальною менструальною та репродуктивною фуункціями, яких було поділено на такі групи: основна (ОГ) А група - 137 жінок із ЛМ, яких надалі для оцінки проведеного лікування розподілено на підгрупи A1 - 55 жінок із ЛМ після лапаро- та гістероскопії із запропонованим лікувальним комплексом (ЛК), А2 - 45 пацієнток із ЛМ після гістероскопії та ЛК, АЗ - 37 жінок із лМ та запропонованим медикаментозним лікуванням без оперативного видалення ЛМ; порівняння (ПГ) Б група - 38 жінок із ЛМ та загальноприйнятим лікуванням.

Усі пацієнтки підлягали детальному традиційному клініко-лабораторному обстеженню в гінекології відповідно до локальних протоколів, які затверджені в даній клініці, щодо ведення пацієнток із матковим фактором безпліддя та наказу Міністерства охорони здоров'я України від 09.09.2013 р. № 787 «Про затвердження порядку застосування допоміжних репродуктивних технологій в Україні». Гормональний статус пацієнток визначали за вмістом у крові лютеїнізуючого гормону (ЛГ), фролікулостимулюючого гормону (ФСГ), естрадіолу (Е2) за традиційними методиками. У даному дослідженні були використані стандартні клініко-лабораторні обстеження згідно з нормативними документами (локальним наказам) надання амбулаторної і стаціонарної акушерсько-гінекологічної допомоги до та після операції міомектомії. Дослідження проводили відповідно до принципів Гельсінської декларації прав людини, Конвенції Ради Європи про права людини і біомедицину та відповідних законів України.

Статистичні методи дослідження виконано за допомогою ліцензійної програми Statistica (версія 10; Statsoft, США). Для обробки кількісних величин застосовували традиційні методи параметричної статистики (середня величина, помилка середньої величини). Дані наведено у вигляді середніх арифрметичних значень та стандартних відхилень. При порівнянні варіаційних рядів враховували достовірні розходження $(p<0,05)$.

РЕЗУЛЬТАТИ ДОСЛІДЖЕННЯ ТА ЇХ ОБГОВОРЕНня. Вік обстежених пацієнток становив $(33,9 \pm 7,8)$ року (26-42 років), ІМТ - $(23,5 \pm 5,2) \mathrm{kг} / \mathrm{M}^{2}$, АМГ - 1,8 $\mathrm{ng} / \mathrm{ml}$ $(0,4-5,2 \mathrm{ng} / \mathrm{ml})$. Тривалість безпліддя - 2-15 років, у середньому $(5,4 \pm 0,5)$ року. Первинне безпліддя діагностовано в 43 пацієнток (24,5\%), а вторинне - у 132 жінок (75,5 \%). Середній вік початку менархе становив $(13,0 \pm 0,5)$ року та характеризувався регулярним менструальним циклом. Подружні пари з чоловічим фрактором безпліддя до даного дослідження не входили. Розвиток лейоміоми матки у кожної третьої пацієнтки слугує основним фрактором безпліддя, але варто зазначити, що у більшості пацієнток діагностовано поєднання ЛМ та супутньої гінекологічної патології, а саме: запальних захворювань органів малого таза, патології ендометрія та ендокринних порушень. Важливу роль також відіграють спадкова схильність; травматизація ендо- й міометрія при проведенні діагностичного вишкрібання порожнини матки з приводу патології ендометрія, порушеної маткової вагітності і при медичному аборті. У нашому центрі для прогнозування результативності програм допоміжних репродуктивних технологій ми оцінили оваріальний резерв обстежених жінок. Отримані результати досліджень свідчать, що в обстежених жінок основної групи на 2-3-й день менструального циклу виявлено зменшення концентрації естрадіолу, при незміненому рівні прогестерону ( $>0,05)$, але було зафіксовано достовірне зниження прогестерону у жінок основної групи й порівняння на 21-й день циклу, що свідчить про наявність лютеїнізації фолікула. Аналіз отриманих даних показав, що рівень пролактину у всіх досліджуваних групах не відрізнявся. Значення лютеїнізуючого та фолікулостимулюючого гормонів у жінок основної групи та групи порівняння були нижчими відносно показників контрольної групи ( $>0,05)$. У жінок основної групи та групи порівняння спостерігали статистично вагоме зменшення рівня естрадіолу в крові $((60,27 \pm 0,004)$ та $(66,69 \pm 0,003)$ нмоль/л). Дані зміни зниження рівня естрогенів у крові пацієнток основної та порівняння 
груп до етапу контрольованої стимуляції яєчників зайвий раз вказують на відхилення в ендокринній фуункції, першочергово гормонопродукуючої фрункції яєчників, яка зумовлена аутоімунними процесами та впливом комплексів антиген-антитіло і біологічно активних амінів на фролікулярний апарат яєчника.

Вважають ФСГ більш достовірно прогностичним критерієм для оцінки оваріального резерву, ніж вік жінки. Для оцінки ймовірного оваріального резерву користувались таблицею 1.

Співвідношення ЛГ до ФСГ в обстежених групах було в межах 1,18-1,2. Даний коесріцієнт дещо нижчий, що можна пояснити порушенням із боку центральної регуляції репродуктивної системи. Для повноцінного розвитку фолікула необхідний фрізіологічний баланс між ФСГ та ЛГ в межах (1,5-2,0). Нами зафріксовано збільшення рівня естрогенів крові обстежуваних пацієнток, та співвідношення ЛГ/ФСГ склало, відповідно: 1,24 та 1,31 на 14-й день МЦ. Проаналізувавши отримані показники гонадотропних гормонів та відсутність суттєвих змін, можемо стверджувати, що задіяні компенсаторні реакції організму при цьому забезпечують овуляцію в 2/3 обстежених пацієнток, тоді як репродуктивна фрункція виявляється значно порушеною та проявляється безпліддям.
Термін «ультразвуковий моніторинг» - це серія ультразвукових досліджень, які виконані в певні дні стимуляції з метою оцінки динаміки росту фолікулів та ендометрія для визначення тактики лікування. Під час проведення першого УзД (2-3-й день менструального циклу) звертаємо увагу на стан ендометрія, міометрія, порожнини матки та маткових труб.

У судинній сітці репродуктивної системи щомісячно відбуваються зміни. Адекватний кровообіг важливий фактор для їх нормального фрункціонування. Пікова систолічна швидкість (ПСШ) кровообігу в судинах строми яєчників - важливий доплерометричний критерій для оцінки ймовірної оваріальної відповіді. У випадку «бідної» відповіді на стимуляцію овуляції середня ПСШ стромальних артерій буде в 2 рази нижчою, ніж при сприятливій відповіді (табл. 2).

Збільшення пульсаційного індексу (ПІ) та індексу резистентності (IP) перисролікулярних судин яєчників жінок із недостатньою відповіддю на стимуляцію та нормальним рівнем ФСГ. Спостерігається позитивна кореляція між кількістю введених гонадотропінів, рівнем ФСГ, ПІ в стромальних артеріях яєчників склав $1,5 \pm 0,4$. Отже, до сракторів ризику недостатньої відповіді відносять низьку ПСШ (менше 10 см/с), збільшення ПІ та IP (табл. 3).

Таблиця 1. Показники ФСГ для оцінки оваріального резерву

\begin{tabular}{|c|l|}
\hline $\begin{array}{c}\text { Концентрація ФСГ на 2-3-й день } \\
\text { циклу, МО/л }\end{array}$ & \multicolumn{1}{|c|}{ Ймовірна відповідь яєчників } \\
\hline $3-8$ & Сприятлива відповідь \\
\hline $8-10$ & Відповідь від сприятливої до помірно зниженої \\
\hline $10-12$ & Задовільна, знижена відповідь \\
\hline $12-17$ & «Бідна» відповідь із низькою частотою настання вагітності \\
\hline$>17$ & Вкрай незадовільна чи негативна відповідь \\
\hline
\end{tabular}

Таблиця 2. Кількість антральних фолікулів

\begin{tabular}{|c|l|}
\hline $\begin{array}{c}\text { Антральний фолікул, d=2-10 мм } \\
\text { в обох яєчниках }\end{array}$ & \multicolumn{1}{|c|}{ Ймовірна відповідь } \\
\hline$<5$ & «Бідна» \\
\hline $5-7$ & «Бідна»-збільшити дозу ФСГ \\
\hline $8-12$ & $\begin{array}{l}\text { Задовільна, помірна частота } \\
\text { настання вагітності }\end{array}$ \\
\hline $13-30$ & Сприятлива \\
\hline$>30$ & Ризик виникнення Сгя \\
\hline
\end{tabular}

Таблиця 3. Показники «бідної» та гіпервідповіді яєчників на стимуляцію

\begin{tabular}{|l|c|c||}
\hline \multicolumn{1}{|c|}{ Показники } & «Бідна» & ГСЯ \\
\hline Вік, роки & $>35$ & $<25$ \\
\hline ІМТ, кг/м² & $>30$ & - \\
\hline ФСГ на 2-3-й день менструального циклу & $>12$ & $<100$ \\
\hline $\begin{array}{l}\text { Е }_{2} \text { на 2-4-й день менструального циклу, } \\
\text { пмоль/л }\end{array}$ & $>300$ & $>76$ \\
\hline Інгібін В на 2-4-й день, пг/мл & $<45$ & $>10$ \\
\hline Об'єм яєчників, см ${ }^{3}$ & $<3$ & $>15$ \\
\hline $\begin{array}{l}\text { Кількість антральних фолікулів d=2-10 мм на } \\
\text { 2-4-й день менструального циклу }\end{array}$ & $<7$ & $>12$ \\
\hline ПСШ артерій строми яєчника, см/с & $<8$ & $<0,75$ \\
\hline ПІ & $>1,6$ & $<0,48$ \\
\hline IP & - & \\
\hline
\end{tabular}


Враховуючи, що рівень інгібіну В є залежним від ФСГ та фрази менструального циклу, за маркер був обраний антимюллерів гормон (АМГ), який не є ФСГ-залежним та не змінюється впродовж менструального циклу. Рівень гормону визначали як: низький - 0,01-0,9 нг/мл; середній - 1,0-2,5 нг/мл; високий - більше 2,5 нг/мл (табл. 4).

Отримано чітку кореляцію між кількістю жінок із підвищеним рівнем загального тестостерону та жінок із підвищеним рівнем АМГ. Відомо, що в перисреричному колі кровообігу андрогени перетворюються на естрон, який за принципом позитивного зворотного зв'язку стимулює секрецію ЛГ. Підвищення рівня ЛГ приводить до значного збільшення секреції андрогенів яєчниками, які в периореричних тканинах також конверсують в естрон, і таким чином хибне коло замикається. Збільшення рівня тестостерону опосередковано спричиняє збільшення концентрації антимюллерового гормону (АМГ) клітинами гранульози яєчників.

Дослідження ендометрія на 6-8-й постовуляторний день дозволяє охарактеризувати стан слизової тіла матки в період максимальної активності жовтого тіла. При достатньо високому рівні оваріальних гормонів у плазмі крові у жінок із регулярним менструальним овуляторним циклом майже в 30 \% випадків виявлено неповноцінну секреторну трансформацію, гіперпластичні процеси та поліпи ендометрія.

Таблиця 4. Концентрація антимюллерового гормону (АМГ) та загального тестостерону в крові жінок на 3-5-й день менструального циклу $(\mathrm{M} \pm \mathrm{m})$

\begin{tabular}{|l|l|c|c|c|}
\hline \hline \multicolumn{2}{|c|}{ Параметри } & $\begin{array}{c}\text { ОГ } \\
(\mathrm{n}=137)\end{array}$ & $\begin{array}{c}\text { ПГ }\left(\begin{array}{c}\mathrm{K} \\
\mathrm{n}=38)\end{array}\right. \\
(\mathrm{n}=32)\end{array}$ \\
\hline \multirow{2}{*}{$\begin{array}{l}\text { Тестостерон (загальний) } \\
0,13-1,08 \text { нг/мл }\end{array}$} & Норма & 30 & 9 & 8 \\
\cline { 2 - 5 } & Нижче норми & 39 & 15 & 13 \\
\cline { 2 - 5 } & Вище норми & 68 & 12 & 11 \\
\hline \multirow{2}{*}{$\begin{array}{l}\text { АМГ, нг/мл } \\
1,0-2,5 \text { нг/мл }\end{array}$} & Норма & 82 & 13 & 10 \\
\cline { 2 - 5 } & Нижче норми & 14 & 11 & 10 \\
\cline { 2 - 5 } & Вище норми & 41 & 14 & 12 \\
\hline
\end{tabular}

ВИСНОВОК. Проаналізувавши отримані дані дослідження, слід сказати, що детальний аналіз оцінки оваріальної відповіді дасть змогу правильно вибрати тактику лікування та дозу препаратів, а також відстежити їх відповідь. Необхідність проведення обґрунтованої комплексної, поетапної та індивідуально підібраної терапії дозволить відновити репродуктивну функцію та підвищити ефективність застосування програм допоміжних репродуктивних технологій у вирішенні питання подолання безпліддя.

ПЕРСПЕКТИВИ ПОДАЛЬШИХ ДОСЛІДЖЕНЬ. Вивчити показники імунного гомеостазу для корекції виявлених змін із метою підвищення ефрективності програм допоміжних репродуктивних технологій. Оцінити есрективність запропонованого лікування в жінок із безпліддям

Зв'язок публікації з плановими науково-дослідними роботами. Дана робота $є$ фррагментом НДР кафедр ТНМУ «Клініко-патогенетичні аспекти діагностики, лікування та профрілактики ускладнень у жінок з порушенням репродуктивної функції та при супутній соматичній екстрагенітальній патології», № державної реєстрації $0116 u 003909$.

\section{СПИСОК ЛІТЕРАТУРИ}

1. Онищук О.Д. Підготовка жінок з безпліддям до запліднення in vitro після невдалих попередніх спроб : авторефр. дис. на здобуття наук. ступеня канд. мед. наук: спец. 14.01.01 «Акушерство та гінекологія» / О. Д. Онищук. - К. : НМАПО імені П. Л. Шупика, 2016.- 28 с.

2. Вдовиченко Ю. П. Лейоміома матки: етіопатогенез, профілактика, діагностика та лікування : огляд літератури / Ю. П. Вдовиченко, О. В. Голяновський, І. В. Лопушан // Здоров'я жінки. - 2012. - № 3. - С. 52-61.

3. Шаповалова А. И. Лейомиома матки и репродукция / А. И. Шаповалова //Журнал акушерства и женских болезней. - 2019. - T. 68. - № 1. - С. 93-101.

4. Штох Е. А. Миома матки. Современное представление о патогенезе и фракторах риска / Е. А. Штох, В. Б. Цхай // Сибирское медицинское обозрение. - 2015. - № 1. C. 22-27.

5. Повышение шансов наступления беременности после миомэктомии в программах ВРТ / А. 3. Хашукоева, М. И. Агаева, М. 3. Дугиева [и др.] // Медицинский совет. 2017. - № 3. - С. 138-142.

6. Сучасні погляди репродуктолога на етіопатогенез та лікування лейоміоми матки / Н. В. Авраменко, Д. Є. Бар- ковський, О. В. Кабаченко [та ін.] // Запорізький медичний журнал. - 2017. - № 3 (102). - С. 381-386.

7. Optimization of metods diagnostics and treatment of submucosal leiomyomas in woman of reproductive age / O. Doroha, I. larotska, A. Vitiuk, H. Strelko // Georgian medical news. - 2019. - Vol. 12 (297). - P. 35-41.

8. Долинский А. К. Роль миомэктомии в преодолении бесплодия / А. К. Долинский // Журнал акушерства и женских болезней. - 2013. - T. LXII, № 1. - C. 42-46.

9. Алексенко О. О. Інтрамуральна лейоміома тіла матки і фертильність : огляд літератури / О. О. Алексенко, Л. Є. Медведєва, М. В. Медведєв // Медичні перспективи. 2015. - Т. 10, № 4. - С. 10-15.

10. Лейоміома матки і безпліддя : огляд літератури / С. В. Хміль, І. В. Корда, Ю. Б. Дроздовська [та ін.] // Вісник соціальної гігієни та організації охорони здоров'я України. 2017. - № 4 (74). - C. 97-103.

11. Sabry M. Innovative oral treatments of uterine leiomyoma / M. Sabry, A. Al-Hendry // Obstet. Gynecol. Int. 2012. - Vol. 2012. - P. 943635.

12. Сыромятникова С. А. Гистероскопия в программах вспомогательных репродуктивных технологий / 
С. А. Сыромятникова, М. И. Базина, А. Т. Егорова // Сибирское медицинское обозрение. - 2013. - № 1. - С. 14-18.

13. Pohl O. Ulipristal acetate - safety and pharmacokinetics following multiple doses of $10-50 \mathrm{mg}$ per day / O. Pohl, I. Osterloh, J. P. Gotteland // J. Clin. Pharm. Ther. - 2013. Vol. 38 (4). - P. 314-320.

14. Tristan M. Mifepristone for uterine fibroids / M. Tristan, L. J. Orozco, A. Steed // Cochrane Database Syst. Rev. - 2012. - Issue 8. - CD 007687.

15. Intramural leiomyoma without endometrial cavity distortion may negatively affect the ICSI - ET outcome $/$ S. Guven, C. Kart, M. A. Unsal, E. Odaci // Reprod. Biol. Endocrinol. - 2013. - Vol. 11. - P. 102.

16. Семеняк А. В. Лейоміома матки та вагітність / А. В. Семеняк, О. М. Юзько, І. Р. Ніцович // Неонатологія, хірургія та перинатальна медицина. - 2018. - Т. 7, № 2 (28) - C. $93-98$

17. Нові погляди на лікування лейоміоми матки в жінок репродуктивного віку / А. Г. Корнацька, О. О. Ревенько,

\section{REFERENCES}

1. Onyshchuk, O.D. (2016). Pidhotovka zhinok z bezpliddiam do zaplidnennia in vitro pislia nevdalykh poperednikh sprob [Preparation of women with infertility for in vitro fertilization after unsuccessful previous attempts]. Candidate's thesis. Kyiv: NMAPO im. P. L. Shupyka [in Ukrainian].

2. Vdovychenko, Yu.P., Holianovskyi, O.V., \& Lopushan, I.V. (2012). Leiomioma matky: etiopatohenez, profilaktyka, diahnostyka ta likuvannia: ohliad literatury [Uterine leiomyoma: aetiopathogenesis, preventive care, diagnostics and treatment: literature review]. Zdorovia zhinky - Women's Health, 3, 52-61 [in Ukrainian].

3. Shapovalova, A.I. (2019). Leiomioma matky i reproduktsiya [Uterine fibroid and reproduction]. Zhurnal akusherstva $i$ zhenskikh bolezney - J. Obstet. Women's Dis., 68 (1), 93-101. DOI: 10.17816/JOWD68193-101 [in Russian].

4. Shtokh, E.A., \& Tskhai, V.B. (2015). Mioma matky. Sovremennoye predstavlenye o patogneze i faktorakh riska [Uterine myoma. Modern views on the pathogenesis and risk factors]. Sibirskoe medytsynskoe obozrenye - Siberian Medical Review, 1, 22-27 [in Russian].

5. Gashukoeva, A.Z., Agaeva, M.I., Dugieva, M.Z., Ermilova, K.A., \& Sukhova, T.N. (2017). Povyshenie shansov nastupleniya beremennosti posle miomektomii v programmah VRT [Increased chances of pregnancy after myomectomy in ART programs]. Meditsinskiy sovet - Medical Council, 3, 138142. DOI: 10.21518/2079-701X-2017-13-138-142 [in Russian].

6. Avramenko, N.V., Barkovskyi, D.Ye., Kabachenko, O.V., \& Letsyn, D.V. (2017). Suchasni pohliady rerproduktoloha na etiopatohenez ta likuvannia leiomiomy matky [Reproductologist's current views on etiopathogenesis and treatment of uterine leiomyoma]. Zaporizkyi medychnyi zhurnal - Zaporozhye Medical Journal, 19, 3 (102), 381-386. DOI: 10.14739/2310-1210. 2017.3.100953 [in Ukrainian].

7. Doroha, O., Iarotska, I., Vitiuk, A., \& Strelko, H. (2019). Optimization of metods diagnostics and treatment of submucosal leiomyomas in woman of reproductive age. Georgian Medical News, 12 (297), 35-41.

8. Dolinskiy, A.K. (2013). Rol miomektomii v preodolenii besplodiya [Role of myomectomy in infertility treatment]. Zhurnal akusherstva i zhenskikh bolezney - J. Obstet. Women's Dis., LXII, 1, 42-46 [in Russian].

9. Aleksenko, O.O., Medvedieva, L.Ye., \& Medvediev, M.V. (2015). Intramuralna leiomioma tila matky i fertylnist: ohliad
І. С. Колесніченко [та ін.] // Репродуктивна ендокринологія. 2017. - № 4 (36). - С. 82-85.

18. Стрижаков А. Н. Возможности и перспективы консервативной миомэктомии с позиций сохранения репродуктивной фуннцииженщины/А.Н.Стрижаков,А.И.Давидов, Е. М. Чочаєва// Анналы хирургии. - 2016. - № 21 (1-2). - С. 32-41.

19. Ефективність гістерорезектоскопії у жінок з безпліддям на фроні лейоміоми матки в програмах допоміжних репродуктивних технологій / С. В. Хміль, Ю.Б.Дроздовська, М. С. Хміль [та ін.] // Вісник соціальної гігієни та організації охорони здоров'я України. - 2018. - № 4 (78). - С. 51-55.

20. Место биполярной гистерорезекции в лечении больных с субмукозной миомой матки / В. Г. Бреусенко, О. И. Мишиева, И. В. Караченцова [и др.] // Журнал акушерства и женских болезней. - 2011. - Т. 60, № 5. - С. 18-24.

21. Тумабаева С. Д. Оценка эфрфективности гистерорезектоскопии в лечении субмукозной миомы матки / С. Д. Тумабаева, А. М. Есенгулова, Ж. Н. Баймуханбетова // Вестник КазНМУ. - 2016. - № 4. - С. 1-3.

literatury [Intramural uterine leyomima and fertility: literature review]. Medychni perspektyvy - Medical Perspectives,10, 4, 10-15 [in Ukrainian].

10. Khmil, S.V., Korda, I.V., Drozdovska, Yu.B., Khmil, M.S., \& Chudiiovych, N.Ya. (2017). Leiomioma matky i bezpliddia: ohliad literatury [Uterine leiomyoma and infertility: literature review]. Visnyk sotsialnoi hihiieny ta orhanizatsii okhorony zdorovia Ukrainy - Bulletin of Social Hygiene and Organization of Public Health of Ukraine, 4 (74), 97-103. DOI: 10.11603/16812786.2017.4.8661 [in Ukrainian].

11. Sabry, M., \& Al-Hendry, A. (2012). Innovative oral treatments of uterine leiomyoma. Obstet. Gynecol. Int., 2012, 943635. DOI: 10. 1155/2012/943635.

12. Syromyatnikova, S.A., Bazina, M.I., \& Egorova, A.T. (2013). Gisteroskopiya v programmah vspomogatelnykh reproduktivnykh tekhnologiy [Hysteroscopy in assisted reproductive technology programs]. Sibirskoe meditsinskoe obozrenie - Siberian Medical Review, 1, 14-18 [in Russian]

13. Pohl, O., Osterloh, I., \& Gotteland, J.P. (2013). Ulipristal acetate - safety and pharmacokinetics following multiple doses of 10-50 mg per day. J. Clin. Pharm. Ther., 38 (4). 314-320. DOI: $10.1111 /$ jcpt.12065.

14. Tristan, M., Orozco, L.J., \& Steed A. (2012). Mifepristone for uterine fibroids. Cochrane Database Syst. Rev., 8, CD 007687.

15. Guven, S., Kart, C., Unsal, M.A., \& Odaci, E. (2013). Intramural leiomyoma without endometrial cavity distortion may negatively affect the ICSI - ET outcome. Reprod. Biol. Endocrinol., 11, 102. DOI: 10.1186/1477-7827-11-102.

16. Semeniak, A.V., Yuzko, O.M., \& Nitsovych, I.R. (2018). Leiomioma matky ta vahitnist [Uterine leiomyoma and pregnancy]. Neonatolohiia, khirurhiia ta perynatalna medytsyna - Neonatology, Surgery And Perinatal Medicine, 7, 2 (28), 9398. DOI: 10.24061/2413-4260.VIII.2.28.2018.14 [in Ukrainian].

17. Kornatska, A.H., Revenko, O.O., Kolesnichenko, I.S., Flaksemberh, M.A., \& Obukhova, H.lu. (2017). Novi pohliady na likuvannia leiomiomy matky $v$ zhinok reproduktyvnoho viku [New views on the treatment of uterine leiomyoma in women of reproductive age]. Reproduktyvna endokrynolohiia Reproductive Endocrinology, 4 (36), 82-85 DOI: 10.18370/23094117.2017.36.82-85 [in Ukrainian].

18. Strizhakov, A.N., Davydov, A.I., \& Chochaeva, E.M. (2016). Vozmozhnosti i perspektivy konservativnoy miomektomii 
s pozitsiy sokhraneniya reproduktivnoy funktsii zhenschiny [Possibilities and prospects of myomectomy from the standpoint of woman reproductive function saving]. Annaly khirurgii -Annals of Surgery, 21 (1-2), 32-41. DOI:10.18821/1560- 9502-2016-211-32-41 [in Russian].

19. Khmil, S.V., Drozdovska, Yu.B., Khmil, M.S., \& Chudiiovych, N.la. (2018). Efektyvnist histerorezektoskopii u zhinok z bezpliddiam na foni leiomiomy matky $v$ prohramakh dopomizhnykh reproduktyvnykh tekhnolohii [Effectiveness of hysterorezectoscopy in women with infertility and uterine fibroids in programs of assisted reproductive technologies]. Visnyk sotsialnoi hihiieny ta orhanizatsii okhorony zdorovia Ukrainy -
Bulletin of Social Hygiene and Health Care Organization Ukraine, 4 (78), 51-55 [in Ukrainian].

20. Breusenko, V.G., Mishieva, O.I., Karachentsova, I.V., Golova, Yu.A, \& Shevchenko, N.A. (2011). Mesto bipolyarnoy gisterorezektsii v lechenii bolnykh s submukoznoy miomoy matki [Bipolar resection in submucose myoma treatment]. Zhurnal akusherstva $i$ zhenskikh bolezney - Journal of Obstetrics and Women's Diseases, 60, 5, 18-24 [in Russian].

21. Tumabaeva, S.D. Esengulova, A.M., \& Baymuhanbetova, Zh.N. (2016). Otsenka effektivnosti gisterorezektoskopii v lechenii submukoznoy miomyi matki [Evaluation of hysteroresectoscopic treatment of submucous uterine fibroids]. Vestnik KazNMU Bulletin KazNMU, 4, 1-3 [in Russian].

Отримано 25.09.20 Прийнято до друку 28.10.20 Електронна адреса для листування: klinica_khmil@ukr.net 